\title{
A Otimização de Estratégias Didáticas através da Análise Contrastiva
}

\section{Lúcia Fulgèncio *}

RESUMO: No uso da língua estrangeira o falante aplica inconscientemente as associações mentais que aprendeu na língua materna. A transferência dos conhecimentos prévios é inevitável porque faz parte do nosso condicionamento cognitivo. Consequentemente, algumas dificuldades são diferentes, dependendo da língua materna do aluno. Durante os procedimentos de ensino da língua estrangeira, a focalização em um ponto ou outro dependerá portanto da L1. Neste artigo são apresentados alguns problemas linguísticos de brasileiros que estudam italiano, observados em corpus real, e também de estudantes de outras origens linguísticas. O objetivo é colocar em evidência que as dificuldades de aprendizagem são diferentes dependendo da língua materna do aluno, e insistir na importância do enfoque contrastivo. Essa proposta didática implica que: (1) é preciso comparar a estrutura da língua estrangeira e a da L1 para que se possam levantar os pontos onde se verifica o transfer e focalizar os problemas específicos dos alunos que têm determinada língua materna; (2) é preciso selecionar os assuntos sobre os quais é interessante concentrar o estudo; (3) é preciso acrescentar aos manuais explicações adicionais que respondam às dificuldades específicas dos falantes de determinada L1. A análise contrastiva permite compreender o porquê de um grande número de erros, conduzindo assim à otimização das explicações e das exercitações.

PALAVRAS-CHAVE: análise contrastiva; transfer; interlíngua; didática de língua estrangeira. 
ABSTRACT: Nell'uso della lingua straniera il parlante è portato a fare inconsciamente le associazioni mentali apprese nella lingua materna. Il transfer delle preconoscenze è inevitabile perché fa parte del nostro condizionamento cognitivo. Da ciò ne consegue che alcune difficoltà sono diverse a seconda della madrelingua dello studente. Nell'approccio glottodidattico, l'enfasi verrà data a un punto o a un altro in base alle specificità della L1. In questo articolo vengono messi in luce problemi linguistici di studenti sia brasiliani che di altre origini linguistiche, tratti da un corpus realistico. L'obiettivo è quello di ribadire che le difficoltà di apprendimento sono differenti a seconda della lingua materna e di insistere sull'importanza dell'analisi contrastiva. L'adozione di tale impostazione didattica ha una ricaduta triplice quale: (1) la necessità di paragonare la lingua straniera e la L1 per individuare i punti dove si verifica il transfer e mettere a fuoco $i$ problemi specifici degli studenti che hanno quella determinata lingua materna; (2) il bisogno di selezionare gli aspetti più importanti su cui concentrarsi; (3) l'esigenza di aggiungere - a titolo integrativo del manuale didattico - le informazioni specifiche per parlanti di una determinata L1. L'analisi contrastiva risponde al perché di un gran numero di errori, e guida il professore alla spiegazione e alla scelta di esercitazioni puntuali.

PAROLE CHIAVE: analisi contrastiva; transfer; interlingua; glottodidattica.

ABSTRACT: When using a foreign language, a speaker unconsciously applies the mental associations valid in the native language. Transfer of previous knowledge is unavoidable because it is part of our cognitive conditioning. Consequently, some difficulties vary according to the learner's native language. When planning language teaching, focus on one or other point will therefore depend on students' L1. In this article some linguistic problems that face Brazilians learning Italian, observed in a real corpus, are presented; some problems typical of learners from other linguistic origins are also considered. The aim is to stress that difficulties vary according to the learner's native language, and to insist on the importance of the contrastive 
approach. This didactic proposal entails that: (1) it is necessary to compare the structure of the foreign language and $L 1$ in order to reveal transfer points and focus specific learning problems of students that have a particular native language; (2) the topics to be preferentially studied must be selected; (3) in handbooks, we should add explanations about the specific problems encountered by speakers of a particular L1. Contrastive analysis allows a better understanding of the reasons for a great number of errors, thus leading to the optimization of explanations and exercises. KEYWORDS: contrastive analysis; transfer; interlanguage; foreign language teaching. 


\section{Ensina-se da mesma forma a alunos de qualquer origem linguística?}

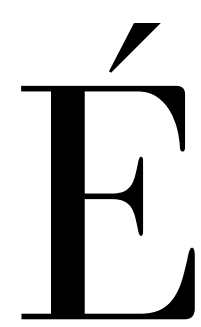

sabido que quando ensinamos italiano para estrangeiros precisamos nos munir de todo material didático disponível, e que devemos utilizar estratégias específicas dependendo da idade dos alunos e dos seus objetivos. Proponho agora outro tipo de consideração, que pode ser expresso por meio dos seguintes questionamentos:

1. No ensino da língua estrangeira, os procedimentos didáticos devem ser diferentes dependendo do background linguístico do aluno - ou seja, dependendo da sua língua materna? Ensina-se da mesma forma a um americano, a um brasileiro ou a um alemão? 
2. É possível utilizar o mesmo manual e os mesmos procedimentos didáticos para todos os alunos, independentemente da sua língua materna? Em outras palavras: o mesmo livro serve para todos os alunos, sejam eles americanos ou brasileiros? Ou o que se deve ensinar depende da língua do estudante?

Neste artigo, vamos propor algumas reflexões acerca desse problema. Tentaremos responder às questões propostas partindo da constatação de que a interlíngua do aluno se baseia em grande parte na estrutura linguística possuída anteriormente, adquirida principalmente através da aprendizagem da língua materna (SELINKER, 1992; GASS; SELINKER, 1994; MEZZADRI, 2003). Esse fato indica que a estrutura da língua materna pode influenciar de forma positiva ou negativa o aprendizado da língua estrangeira, e pode propor dificuldades específicas para a aquisição de um ou outro sistema linguístico (DANESI e DI PIETRO, 2001; KATERINOV, 1980; JAMES, 1980; BATTAGLIA e NOMURA, 2008; CORDER, 1983; FISIAK, 1981; BROWN, 1994; CILIBERTI, 1994; FULGÊNCIO e BASTIANETTO, 1993; DEL RÉ et al., 2006). Essas observações nos levam a considerar que o professor de italiano deve sempre levar em conta a importância da elaboração de descrições contrastivas e da análise de erros no ensino da língua a brasileiros.

\section{Evidências do processo de transfer linguístico}

Para responder às questões levantadas anteriormente vamos partir de algumas observações gerais.

Provavelmente, todos já ouviram algum estrangeiro enquanto fala e, pelo modo como se exprime, pelos seus erros de construção ou de pronúncia, frequentemente podemos determinar a origem linguística desse falante - se é americano, francês ou chinês, por exemplo. O modo específico de usar a língua estrangeira denuncia a proveniência linguística do falante. Isso acontece porque os traços e as características da língua materna (L1) se refletem no uso da língua estrangeira.

O sotaque, por exemplo, é a manifestação mais clara desse fenômeno: é possível reconhecer a origem linguística de uma pessoa a partir da sua pronúncia. $\mathrm{O}$ falante, condicionado pelo sistema fonológico da língua materna, tende a transferir para a língua estrangeira esses mesmos 
condicionamentos fonológicos. Essa transferência acontece não só no campo da fonética, mas se manifesta também em todos os demais aspectos da língua: na sintaxe, na semântica, no discurso, na pragmática, e assim por diante.

Provavelmente, todos os professores de italiano já tiveram oportunidade de observar em seus próprios alunos certas produções que têm um quê de língua nativa, e já puderam confirmar na prática que realmente existe a tendência em transferir para o italiano as estruturas, construções e estilo correspondentes aos da língua materna. Analisando a produção escrita ou oral dos aprendizes podemos constatar que uma parte significativa dos erros se origina do fato de que muitas vezes o aluno constrói as estruturas em língua estrangeira baseando-se na estrutura da língua nativa.

O apoio na língua materna tem também seu lado positivo: se a estrutura das duas línguas é coincidente, o aluno lucra ao aproveitar um conhecimento linguístico que já possuía. Por exemplo: americanos que aprendem italiano têm mais facilidade em estabelecer a distinção de uso entre os verbos avere e esserci, já que existe paralelismo semântico e morfossintático entre esses itens e os verbos correspondentes em inglês: avere / to have, e esserci / there to be. Devido então à semelhança entre as formas do italiano e do inglês, os alunos americanos têm a aprendizagem facilitada pelo transfer positivo.

Já em português, ao contrário, os verbos italianos avere e esserci convergem para a mesma forma lexical ter, o que dificulta a distinção semântica e formal. Além disso, os falsos cognatos $h a$ em italiano (que só pode ser traduzido em português por tem e nunca por há) e a forma do português há (que só pode ser traduzida em italiano por c'è ou ci sono, e nunca por ha) ajudam a confundir o aluno na distinção entre cada uma dessas formas e seus usos.

Essas observações relativas ao efeito da interferência da língua materna na aprendizagem da língua estrangeira não tratam de nenhuma novidade, muito embora tenham sido contestadas no passado e negligenciadas por vários especialistas em didática (veja-se, a esse respeito, KATERINOV, 1980, e ainda BESSE e PORQUIER, 1991; LEE e VANPATTEN, 1995; SANDERS, 1981).

Os erros oriundos da interferência do sistema da língua materna sobre as produções em língua estrangeira são somente uma categoria dos erros possíveis. Há certamente vários outros tipos além daqueles devidos ao transfer, como, por exemplo, os erros provenientes de dificuldades intralinguísticas, que decorrem da própria complexidade interna do sistema da língua que se aprende. 
Como se sabe, os erros oferecem pistas importantes sobre as hipóteses formuladas pelos alunos em relação às regras da língua. Em casos de interferência interlinguística, os erros revelam que a hipótese formulada pelo aluno é a de que haveria paralelismo e simetria entre as estruturas dos dois sistemas linguísticos: o da língua que aprende e o da sua própria língua nativa.

Acontece, no entanto, que um brasileiro que estuda italiano tem dificuldades específicas e comete erros como os seguintes (extraídos de corpus real ${ }^{1}$ ):

$$
\begin{aligned}
\text { (1) * Mi preoccupo con questo } & \text { problema. }^{2} \text { (italiano) } \\
\text { Me preocupo } & \text { com esse problema. (português) }
\end{aligned}
$$

Nesse caso, verifica-se um problema de regência, motivado pelo uso de verbos semelhantes nas duas línguas (preoccuparsi - em italiano / preocupar-se - em português), sendo que em português o verbo seleciona a preposição com - que aliás também existe em italiano (con) embora não seja usada nesse mesmo contexto estrutural. A construção agramatical do aluno segue o modelo da diátese do verbo português preocupar-se; mas em italiano, de forma diferente, o verbo preoccuparsi seleciona as preposições di ou per (uma frase adequada seria Mi preoccupo di questo problema.). O exemplo (1) expõe a vantagem do tratamento contrastivo sobretudo quando se trata de línguas que pertencem à mesma família.

Vejamos outro exemplo de interferência:

$$
\begin{array}{lll}
(2) * \quad & \text { Vado } & \text { al cinema con te } . \\
& \text { Vou } & \text { ao cinema com você. }
\end{array}
$$

Nesse caso, o aluno emprega o verbo ir usado em português, traduzido em italiano por andare, numa construção em que o verbo andare é inadequado, já que, em vez disso, em italiano seria necessário escolher o verbo venire.

O terceiro exemplo apresenta vários erros motivados pela estrutura da L1:

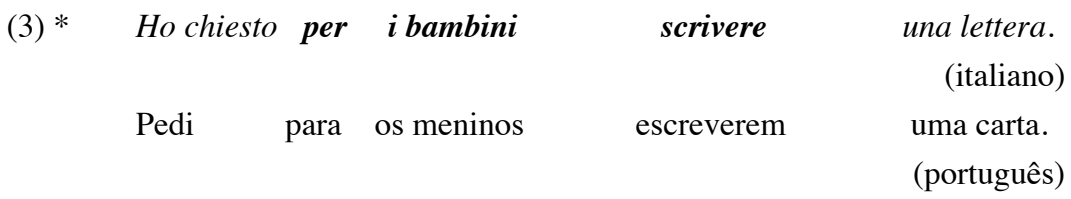

$1 \mathrm{O}$ corpus de onde foram extraídos os exemplos é composto de enunciados orais espontâneos produzidos por alunos de nível B2, coletados durante curso de 'Produção oral' ministrado na UFMG em 2010.

2 Seguindo a praxe linguística, usa-se o símbolo * para indicar uma estrutura agramatical, ou seja, uma construção que um falante nativo não produziria e não consideraria aceitável. 
No exemplo (3), o estudante usa uma estrutura paralela à do português, em que aparece a preposição per (correspondente ao português para) e um sujeito explícito (o sintagma nominal $i$ bambini) diante de um verbo no infinitivo (scrivere), o que não é permitido no mesmo contexto linguístico em italiano ${ }^{3}$.

Nesses exemplos, é possível constatar a reprodução em italiano das estruturas da língua do aprendiz, em que aparecem claramente calques de construções da L1. Observa-se nesses casos que o aluno tem a tendência a transferir para o italiano a estrutura da sua língua nativa.

O transfer ocorre automaticamente: no uso da língua estrangeira o falante aplica de forma inconsciente os seus conhecimentos prévios e as associações que aprendeu na língua materna (como no caso da colocação associada à diátese verbal, no exemplo 1) ou em outras línguas estrangeiras aprendidas anteriormente. Não é que o aprendiz pense na sua língua (ou em outra língua) e faça a tradução para o italiano. O processo de transfer acontece sem que o aluno perceba, e portanto não seria adequada nenhuma posição negativa com relação ao transfer - o que não implica, por outro lado, uma atitude leniente com relação à produção agramatical, o que deve ser evitado. O processo de transferência de conhecimentos prévios faz parte do nosso condicionamento cognitivo, ou seja, do modo como o cérebro funciona para aprender.

\section{Aprendizagem tem como base os conhecimentos prévios}

O processo de transfer ocorre não somente quando o estudante aprende uma língua estrangeira, mas também em qualquer outro tipo de aprendizagem. Vamos pensar em como aprendemos a executar uma atividade. Por exemplo, vamos imaginar uma pessoa que já sabe dirigir carros e quer aprender a guiar um ônibus. As dimensões dos dois veículos são diferentes, as marchas podem ser diferentes, mas o motorista tem conhecimentos que pode aproveitar: ele sabe que tem de apertar o freio, sabe como funciona a embreagem e para onde girar o volante, por exemplo. Grande parte dos seus conhecimentos sobre como dirigir será transferida para a nova atividade. Vamos imaginar agora uma pessoa que sabe tocar piano e se senta diante de um órgão elétrico: ela vai tocar baseando-se no que sabe sobre o piano, como a posição das notas no teclado. Ou seja: o indivíduo transfere os conhecimentos prévios que possui a respeito de uma atividade para executar outra atividade semelhante.

Do ponto de vista psicológico, quando enfrentamos uma situação nova - como quando

3 Em italiano um verbo no infinitivo admite sujeito não explícito, elíptico, e correferencial a outro sujeito presente na sentença, como no caso de Silvia vuole mangiare, em que o sujeito de mangiare é correferencial ao de vuole; mas não admite construções com SN explícito, como por exemplo a que corresponde a os meninos escreverem, onde em português aparece o infinitivo flexionado. 
aprendemos uma língua estrangeira - aplicamos o que já sabemos (POSTMAN, 1971). Diante de uma situação nova induzimos as soluções com base nas nossas experiências precedentes. Segundo Postman,

A aprendizagem é um processo cumulativo. Quanto mais um indivíduo adquire conhecimentos e habilidades, mais provável é que a nova aprendizagem seja moldada por suas experiências e atividades passadas. Um adulto raramente aprende algo totalmente novo; por mais desconhecida que seja a tarefa, a informação e os hábitos que ele adquiriu no passado vão ser o seu ponto de partida. Portanto, a transferência de habilidades adquiridas em situações precedentes para as novas situações faz parte de praticamente toda aprendizagem. Nesse sentido o estudo do transfer é coextensivo com a investigação sobre a aprendizagem. (1971, p. 1019) ${ }^{4}$

Também na aprendizagem de uma língua estrangeira o aluno parte do que já sabe sobre as línguas e do que já adquiriu quando aprendeu a língua materna. Por isso, os conhecimentos e as habilidades precedentes são automaticamente transferidos para as novas situações. Esses conceitos são patentes não somente no âmbito específico da didática, mas também em outros campos científicos, como o da antropologia. No Museu de História Natural de Nova York encontra-se a seguinte informação:

As crianças aprendem sozinhas a língua materna, simplesmente ouvindo e vendo as pessoas a seu lado. [...] À medida que a criança fica mais velha, seu cérebro fica “conectado" às línguas que já aprendeu. Isso explica por que motivo é geralmente mais difícil para os adultos aprenderem uma nova língua com fluência. (American Museum of Natural History, Nova York, quadro intitulado Learning language, grifo nosso)..$^{5}$

Constata-se então o reconhecimento da importância e da influência das línguas aprendidas anteriormente sobre a língua target (isto é, sobre a língua que se procura aprender). Segundo Mezzadri, “[...] risulta evidente la necessità di affrontare le problematiche relative alle

\footnotetext{
4 Texto original: «Learning is a cumulative process. The more knowledge and skills an individual acquires, the more likely it becomes that his new learning will be shaped by his past experiences and activities. An adult rarely, if ever, learns anything completely new; however unfamiliar the task that confronts him, the information and habits he has built up in the past will be his point of departure. Thus transfer of training from old to new situations is part and parcel of most, if not all, learning. In this sense the study of transfer is coextensive with the investigation of learning.» (tradução nossa). 5 Texto original completo: «Children teach themselves a native language simply by listening and watching the people around them. This can happen with any language, from Navajo to Nepali. As children get older, their brains become "wired" for the languages they've learned. This explains why learning to speak a new language fluently is usually harder for adults.»
} 
interferenze causate dalla madrelingua dello studente, da altre lingue apprese in precedenza [...]" (2003, p. 187).

A interferência da língua materna é inquestionável empiricamente - basta observar a produção dos estudantes. E será diferente dependendo da língua nativa do aprendiz (e das outras línguas que aprendeu antes). Por exemplo, um brasileiro que estuda italiano tende a produzir frases do seguinte tipo, em que o aluno repete a estrutura do português:

$$
\begin{aligned}
& \text { (4) * Parla ad alta voce per lui ascoltare. (italiano) } \\
& \text { para ele escutar (português) }
\end{aligned}
$$

Em italiano, a construção dessa sentença requer o uso do subjuntivo, e não do infinitivo, proibido nesse caso. O exemplo (4) deveria ser substituído por algo como "Parla ad alta voce perché lui ti possa ascoltare".

Um americano, por outro lado, comete outros tipos de erros que nunca seriam cometidos por brasileiros. Um dos problemas para os anglófonos, que não acontece com quem é de origem linguística românica, é a identificação do gênero das palavras, como se observa no texto seguinte, extraído de uma carta escrita por uma aluna americana:

(5) * Stavo pensando della mia problema ( $\mathrm{mmmm}$, non è una problema ... ma devo fare un decisione subito).

Um americano também pode ter problemas com relação à inserção ou não do artigo numa

\begin{tabular}{|c|c|c|c|}
\hline (6) * & $\begin{array}{l}\text { La sintassi } \\
\text { The syntax }\end{array}$ & $\begin{array}{l}\boldsymbol{d i} \\
\text { of }\end{array}$ & $\begin{array}{l}\text { italiano } \\
\text { Italian }\end{array}$ \\
\hline
\end{tabular}
estrutura nominal, como no caso seguinte (extraído de corpus real):

Observe-se que em (6) não aparece o artigo na construção correspondente em inglês. Para estudantes brasileiros ou espanhóis, ao contrário, essas construções não apresentam dificuldade porque são paralelas às estruturas da L1 .

Um alemão, assim como os americanos (mas diferentemente dos brasileiros), terá problemas relativos à distinção perfeito/imperfeito, como se vê no texto apresentado por Katerinov (1980, 
p. 47), obtido a partir da composição de um aluno alemão:

(7) * Una volta un francese faceva con la sua macchina un viaggio attraverso l'Austria. Visitava molte città e vedeva il paesaggio con le sue montagne e laghi.

A escolha entre o uso do aspecto perfectivo ou imperfectivo no tempo passado é difícil para um alemão, mas fácil para um brasileiro ou um francês, já que também em português e em francês existem esses mesmos tempos e aspectos verbais e, grosso modo, os mesmos usos. É portanto comprovado que as dificuldades são diferentes de acordo com a língua nativa do aprendiz.

\section{Outros tipos de erros}

Como mencionado anteriormente, o transfer não é a única fonte de erros. Existem outros tipos de erros, como os devidos a interferências internas, como quando o aluno opera generalizações onde elas não são adequadas, e amplia o campo de atuação de uma regra atingindo casos em que ela não se aplica, porque constituem excepcionalidades. Vejam-se os exemplos abaixo:

\begin{tabular}{|c|c|c|}
\hline (8) & * se io dassi & (em vez de se io dessi) \\
\hline (9) & * io ando & (em vez de io vado) \\
\hline
\end{tabular}

Esses são exemplos de hipergeneralização ocorrida dentro do próprio sistema linguístico italiano: o discente hipotetiza uma regra e a estende a todo o universo linguístico por meio de analogias, aplicando a hipótese também a casos especiais que são irregulares e não seguem a regra. O aprendiz raciocina mais ou menos do seguinte modo: "se com o verbo mandare se diz se io mandassi, então com o verbo dare se deve dizer se io dassi; e também: se no presente do verbo mandare se diz io mando, com o verbo andare provavelmente se diz io ando" - e assim é projetado o erro, já que a generalização não se aplica a esses casos específicos.

Os erros de hipergeneralização podem ser encontrados também na língua das crianças que estão aprendendo a língua materna, como na fala autêntica de uma menina italiana de dois anos 
que disse "*ho coprito la bambola", e também "*nonno, guarda le mie moti”. São erros que evidenciam as generalizações, ou seja, as regras da língua que o aprendiz está formulando na mente.

Há ainda diversos outros tipos de erro, como os deslizes de performance cometidos durante a produção do enunciado: o falante produz uma estrutura inadequada mesmo sabendo que deveria ter dito algo diferente, e mesmo sabendo corrigir sozinho o deslize. Os erros de produção são desvios que indicam a falta de automatismo das noções aprendidas e sugerem exercitação insuficiente (KATERINOV, 1980, p. 26).

Apesar de haver diversos tipos de erros, não há dúvida de que uma porcentagem expressiva decorre de interferências externas, ou seja, da transferência de estruturas sintáticas, lexicais e pragmáticas existentes no âmbito da língua materna.

\section{Pesquisas sobre a tipologia dos erros}

A partir do exame de produções escritas espontâneas em italiano, feitas por alunos brasileiros de níveis iniciais, foi elaborado um levantamento que elencou 280 construções agramaticais. A análise desse corpus demonstrou que em $68 \%$ dos casos o erro poderia estar relacionado à cópia das construções paralelas em língua materna (CIRAVEGNA; NEVES, 2004).

Em outra pesquisa, Fulgêncio e Albernaz (2013) isolaram somente o problema da escolha lexical das preposições em caso de regência verbal. Foram selecionados 50 verbos italianos que têm valência diferente da dos verbos correspondentes em português, como por exemplo nos seguintes pares italiano/português: pensare a / pensar em; avvicinarsi a / aproximar-se de; contare su qualcuno / contar com alguém; contribuire a / contribuir para. Os verbos foram inseridos em contexto, em frases com sentido completo, nas quais faltava somente a preposição. A partir desses testes cloze, foi solicitado a alunos dos níveis A2 e B1, de diferentes turmas e diferentes escolas de ensino de italiano, que preenchessem as frases com a preposição conveniente. Nesse caso, a porcentagem de erros decorrentes de transfer foi de $73 \%$.

Essas pesquisas confirmam a hipótese de que em alguns enunciados o estudante tende a reproduzir em italiano as construções da sua língua nativa. Outros estudos corroboram essa conclusão e também confirmam a força de processos de interferência, como a pesquisa realizada por Zucchi e Casini (2009), que apresenta a reflexão de alunos brasileiros sobre a causa de erros 
em língua italiana.

O reconhecimento do papel exercido pela língua materna na aprendizagem de uma segunda língua foi uma das maiores descobertas da didática contemporânea no campo do ensino de língua estrangeira. $\mathrm{O}$ modelo teórico que propõe a construção da interlíngua pelo aprendiz incorpora parte da língua materna e assim reconhece a tendência à transferência do sistema da língua nativa na construção do sistema da língua estrangeira estudada.

\section{$\mathbf{1}^{\mathrm{a}}$ consequência}

A partir do que foi dito conclui-se que as dificuldades são diferentes dependendo da língua nativa de cada aluno. É verdade que a língua tem irregularidades internas, mas as dificuldades e os erros não são decorrentes somente das dificuldades intrínsecas ao sistema da própria língua: se assim fosse, todos os alunos, de qualquer nacionalidade, cometeriam os mesmos erros e teriam os mesmos problemas, o que não é verdade. O que se verifica é justamente o contrário: grande parte dos erros e dos problemas de aprendizagem da língua estrangeira tem relação direta com a língua materna, e não só com o sistema interno da língua aprendida. De fato, retomando as observações precedentes:

um americano comete erros como os seguintes (exemplos reais, produzidos por estudantes de nível A2):

(10) * Devo salvare i miei soldi per dopo la laurea. (do inglês to save money)

(11) * Voglio parlare italiano, amo italiano. $\quad$ (do inglês I love Æ Italian.)

Um francês diz

(12) * La sala era piccola e confortabile. (em francês, "confortable")

Um alemão, por outro lado, comete erros como

(13) * Quel pomeriggio era difficile. (em alemão, não existe a divisão aspectual perfeito / imperfeito $)^{6}$

6 Exemplos reais do francês e do alemão apresentados por Katerinov (1975, p. 47 e 48). 
E um brasileiro, ao contrário, comete erros como os seguintes (extraídos todos de corpus real):

(14) * Dopo pensare molto..." (em português depois de pensar muito - usa-se o infinitivo simples).

(15) * Sapevo che lui verrebbe. (em português Eu sabia que ele viria - não se usa o tempo composto na formulação desse contexto).

(16) *Ho tutto che ho bisogno. (em português informal tenho tudo que preciso - a preposição não é exigida antes do pronome relativo).

(17) *Questo è un libro per le persone leggere velocemente. (em português esse é um livro para as pessoas lerem depressa - aparece um sujeito explícito antes do infinitivo, o que não seria possível em italiano).

(18) *Dipende del libro. (em português depende do livro - a preposição selecionada pelos verbos dipendere/depender é diferente nas duas línguas).

(19) Sto cercando di fare con che lo studente capisca quello che dico. (em português estou tentando fazer com que o aluno entenda o que eu digo - aparece a estrutura fazer com que, que não pode ser traduzida literalmente para o italiano).

Vê-se, portanto, que os problemas são diferentes dependendo da língua materna e que as agramaticalidades apresentadas parecem originar-se do transfer que parte das construções em língua materna. Note-se que os problemas apresentados pelos brasileiros (exemplos 14 a 19) não são, em geral, esclarecidos e nem mesmo mencionados nas gramáticas de ensino de italiano para estrangeiros. Por isso, o aluno muitas vezes erra, porque nem mesmo conhece a impossibilidade da construção paralela em italiano.

É portanto necessário comparar a língua que se aprende com a L1 para detectar as diferenças entre os dois sistemas e focalizar os problemas específicos dos alunos que têm aquela determinada língua materna. 


\section{$2^{\mathrm{a}}$ consequência}

Para formular a segunda consequência, podemos proceder ao seguinte raciocínio: se os problemas são diferentes dependendo da língua materna, não é didaticamente conveniente tratar com a mesma ênfase todas as questões linguísticas apresentadas nos manuais. Em turmas homogêneas (onde todos os alunos têm a mesma origem linguística, como acontece geralmente no Brasil), é preciso selecionar os aspectos que apresentam dificuldade. Em outras palavras, nem todos os pontos gramaticais incluídos nos livros merecem ser tratados com a mesma ênfase. $\mathrm{O}$ foco e a exercitação devem ser dirigidos sobretudo para os aspectos que apresentam dificuldade de aquisição.

Convém então decidir qual aspecto linguístico deverá ser exercitado, e qual poderá ser "saltado" ou pouco treinado. Para tanto é necessário conhecer as diferenças entre os sistemas linguísticos - o italiano e o da língua do aluno - para que seja possível concentrar o estudo nos pontos de maior dificuldade para o grupo de pessoas em vista.

Para identificar essa diferença, usa-se a análise contrastiva, comparando as estruturas das duas línguas. Mas só a análise contrastiva não é suficiente: é preciso também verificar o que acontece na prática e quais são os erros recorrentes que podem ser atribuídos à interferência. A análise dos erros deve ser então somada à análise contrastiva, compondo os instrumentos à disposição do professor para auxiliá-lo a identificar não só quais são os problemas, mas também qual pode ser sua causa (ou seja, qual é o tipo de hipótese formulada pelo estudante e o tipo de estrutura que possivelmente estaria interferindo na construção adequada do enunciado).

Para Graddol (2009) “o melhor professor é o que fala também a língua do aluno”, justamente porque o falante bilíngue pode reconhecer os pontos de interferência e de dificuldade daquele grupo específico de alunos.

\section{$3^{\text {a }}$ consequência}

Se a língua materna está na base da inadequação de algumas construções de alunos estrangeiros, é preciso que o professor acrescente ao material apresentado nos manuais as explicações relativas aos pontos de diferença entre o sistema do italiano e o da língua materna do aprendiz, que muitas vezes não são previstos nos manuais de ensino. Os livros elaborados para estudantes de qualquer nacionalidade não poderiam salientar as diferenças entre a língua que se ensina e a língua específica do aluno. Portanto, muitas vezes os livros didáticos não apresentam as explicações de que os alunos precisam para conhecerem a impossibilidade de certas construções, inadequadas em italiano mas possíveis na língua nativa. 
Por exemplo, quando um brasileiro diz:

(20) * Lui ha parlato che stava stanco

o verbo parlare é usado no lugar de dire porque em português não existe a distinção entre dizer e falar e se admite tanto a construção dizer que quanto falar que + oração objetiva. Mas as gramáticas geralmente não apresentam explicitamente o impedimento da estrutura *parlare che; sendo assim, o aluno terá a tendência a usar em italiano o léxico paralelo e a construção do português, produzindo uma estrutura agramatical em italiano.

É portanto indispensável adicionar ao material didático a apresentação de pontos de assimetria entre os sistemas do italiano e o da língua materna, que a análise de erros evidencia como pontos-chave em que há a tendência ao erro.

\section{Conclusão}

Na didática do italiano como língua estrangeira existem aspectos que merecem ênfase especial, dependendo da língua nativa do estudante. Alguns elementos devem ser enfatizados para alunos americanos, mas não para brasileiros, por exemplo. A ênfase em um ponto ou outro vai depender da língua materna do aluno. A descrição contrastiva das duas línguas permite que o professor faça o levantamento dos aspectos que requerem mais atenção e daqueles que não necessitam destaque.

Convém alertar que a análise contrastiva constitui somente um subsídio que deve ser integrado com outros elementos de suporte didático. Uma aquisição mais eficiente do italiano pode ser obtida ao se somarem diversas estratégias a diferentes técnicas metodológicas.

Concluímos portanto que a análise contrastiva e a análise de erros esclarecem para o professor as dificuldades dos alunos, uma vez que (a) em primeiro lugar, permitem que o professor identifique os aspectos que não necessitam de ênfase (se a estrutura do italiano coincide com a da língua do aluno); e (b) em segundo lugar, permitem que sejam acrescentadas ao manual as explicações que às vezes não estão disponíveis nas gramáticas, dirigindo assim as explicações e as exercitações, no interesse da otimização das estratégias didáticas. 


\section{Referências}

BATTAGLIA, M. H. V.; NOMURA, M. (org.) Estudos linguísticos contrastivos - em alemão e português. São Paulo: Annablume, 2008.

BESSE, H.; PORQUIER, R. Grammaires et didactique des langues. Luçon (França): Didier, 1991.

BROWN, H. D. Principles of language learning and tezching. New Jersey: Prentice Hall, 1994.

CILIBERTI, A. Manuale di Glottodidattica. Firenze: La Nuova Italia, 1994.

CIRAVEGNA, T.; NEVES, T. L. Análise de erros - uma pesquisa empírica. Comunicação apresentada na Fundação Torino, Belo Horizonte, 2004.

CORDER, S. P. Introduzione alla linguistica applicata. Bologna: Il Mulino, 1983.

DANESI, M.; DI PIETRO, R. L'analisi contrastiva per l'insegnamento della seconda lingua. Roma: Armando Editore, 2001.

DEL RÉ, A. et al. Aquisição da linguagem: uma abordagem psicolinguística. São Paulo: Editora Contexto, 2006.

FISIAK, J. (ed.). Contrastive linguistics and the language teacher. Oxford: Pergamon Press, 1981.

FULGÊNCIO, L.; ALBERNAZ, P. Estudo sobre o uso das preposições em construções verbais italianas. In XV Congresso da ABPI, 2013. Vitória. Caderno de Resumos - XV Congresso da ABPI. Vitória: Gráfica da UFES, p. 63, 2013

FULGÊNCIO, L.; BASTIANETTO, P. In italiano - Manual de gramática contrastiva para falantes do português, vol. 1 e 2. Perugia: Guerra, 1993.

GASS, S. M.; SELINKER, L. Second language acquisition. New Jersey: Lawrence Erlbaum Associates, 1994.

GRADDOL, D. Entrevista, 2009.

http://g1.globo.com/Noticias/Vestibular/0,,MUL1368465-5604,00-MELHORES+PROFESSORES + D

E+INGLES+NAO+SAO+BRITANICOS+NEM+AMERICANOS+DIZ+LINGUI.html. Acesso: 27.05.2013.

JAMES, C. Contrastive analysis. Singapore: Longman, 1980.

KATERINOV, K. L'analisi contrastiva e l'analisi degli errori di lingua applicata all'insegnamento dell'italiano a stranieri. Perugia: Guerra, 1980.

LEE, J. F.; VANPATTEN, B. Making communicative language teaching happen. New York: McGrawHill, 1995.

MEZZADRI, M. I ferri del mestiere. Perugia: Guerra, 2003.

POSTMAN, L. Transfer, Interference and Forgetting. In KLING, J. W.; RIGGS, L. A. (ed.). Woodworth 
and Schosberg's experimental psychology. New York: Holt, Rinehart and Winston, 1971.

SANDERS, C. Recent developments in contrastive analysis and their relevance to language teaching. In FISIAK, J. (ed.). Contrastive linguistics and the language teacher. Oxford: Pergamon Press, 1981.

SELINKER, L. Rediscovering interlanguage. London: Longman, 1992.

ZUCCHI, A. M. T.; CASINI, C. Fai attenzione in questo! Apprendenti brasiliani di italiano lingua straniera di fronte a distrattori basati sui loro errori, 2009. http://www.valico.org/pubblicazioni/Zucchi\%20 Casini\%20pre-publication.pdf. Acesso: 27.05.2013. 